\title{
Peripartum cardiomyopathy (PPCM), 2021: Dialogue with PPCM mothers
}

\author{
James D Fett ${ }^{1,2 *}$ \\ ${ }^{1}$ Retiring Co-Director, IPAC (Investigations of Pregnancy-Associated Cardiomyopathy), University of Pittsburgh Medical Center, Pittsburgh, USA \\ ${ }^{2}$ Courtesy Medical Staff, Hospital Albert Schweitzer, Deschapelles, HAITI
}

\section{Do I have PPCM or am I developing PPCM?}

PPCM is defined as the development of heart failure during or immediately after pregnancy. Officially, heart failure in this setting is defined as left ventricular ejection fraction (LVEF) of $45 \%$ or less [1-3]. However, that level does not define those who are identified earlier and their LVEF may be greater than $45 \%$. In addition, LVEF impairment only describes systolic dysfunction heart failure; and PPCM also involves diastolic dysfunction heart failure-with or without preserved LVEF. Hence, newer definitions must include both systolic and diastolic dysfunction. Similar signs and symptoms may be seen with either and the treatment is also similar [1-5]. It helps in assessing both risks for development of PPCM and existence of early pregnancyassociated cardiomyopathy (PAC) to do blood testing that includes B-type Natriuretic Peptide (BNP), soluble fms-like tyrosine kinase (sFLT1) and Placental Growth Factor (PGF) [6].

\section{OK, I have PPCM, how severe is it?}

Working with hundreds of PPCM mothers and collaborating with research colleagues, we have found that any subject with PPCM has the potential for rapid decline. It is better to consider any and every subject with PPCM as having a very serious and severe condition. Early recognition and effective full treatment are the best and safest approach $[6,7]$.

\section{What would be the best treatment for me?}

It is important to provide treatment that impacts the pathophysiological mechanisms of PPCM. These evidence-based treatments are identified [1-7] and include tolerable dosages of betablockers (BB) plus ACE-Inhibitors (ACEI) or angiotensin-2-receptor blockers (ARB) or BB plus ARB plus Neprilysin Inhibitor (NI). The latter two, ARB (Valsartan) + NI (Sacubitril) are found in Entresto. This combination of medications is important because the combination works synergistically to provide greater benefit than any one of those used alone. Tolerable dosages of $\mathrm{BB}+$ Entresto appear to be the best combination for those who present with LVEF $\leq 45 \%$.

Should PPCM mothers stop breastfeeding? We have not yet determined for certain that lactating hormone prolactin inhibition treatment with bromocriptine should be used in the treatment of PPCM [8-11]. Earlier reports failed to demonstrate a statistically significant difference between "users" and "non-users" of bromocriptine, and did not include subjects of African heritage, as compared to the IPAC (Investigations of Pregnancy-Associated Cardiomyopathy) study with $30 \%$ of subjects having African heritage [11]. We are not yet certain that the $16-\mathrm{kDa}$ prolactin metabolite of lactating hormone prolactin plays the same cardiotoxic role in human PPCM as has been suggested in the mouse model [8]. The lack of a clinically useful test had also impaired progress in this area. Moreover, human prolactin may be far more resistant to Cathepsin D cleavage into the putative cardio-toxic fragment than appears to be the case in the mouse model.

Bromocriptine had been found many years ago to precipitate dangerous vaso-occlusive side effects when used to stop lactation in those who did not choose to breastfeed; and as a consequence, had been withdrawn in 1994 by the Food and Drug Administration for that purpose. Now, those dangerous side effects appear to be preventable by the use of adequate anti-coagulation, which is accepted by most as also advisable to use in PPCM subjects with diagnostic LVEF below $35 \%$. When bromocriptine is used, it should be accompanied by the concomitant anticoagulation of all subjects, no matter what the level of LVEF.

Further study of this potential tool that includes both "users" and non-users" control subjects will provide the answers we need. A recent small, controlled study out of Uzbekistan suggests some encouraging differences; however, the heart failure treatment given is not indicated in the English language abstract, making assessment difficult, since the full article is available only in Russian [12]. Despite potential benefit, I urge caution in the use of bromocriptine until we have the results of additional research available. In addition, many new mothers wish to breastfeed; and in many areas if the world, babies die without affordable alternative to breast milk [13]. We in IPAC are preparing to launch an additional study of this, involving approximately 40 medical centers in North America in 2021.

\section{How do I know if I am responding to treatment and what tests should I monitor during my treatment?}

It takes time for the signs and symptoms to disappear; but they will, and they do. Your weight daily will be an indicator of loss of excess retained fluid. If you have had heart rates over 100 beats per minute, that will decrease, both as a result of improved heart function and with slowing from treatment with the BB. Monitoring blood BNP will show gradual drop into normal range. What is your score on the "Self-Test?" (Figure 2) [12]. This tests costs nothing and your score

${ }^{\star}$ Correspondence to: James D. Fett, Retiring Co-Director, IPAC (Investigations of Pregnancy-Associated Cardiomyopathy), University of Pittsburgh Medical Center, Pittsburgh, 2331 Mt. Hood Court SE, Lacey, WA 98503, USA, E-mail: fett.sprunger@comcast.net

Received: January 05, 2021; Accepted: January 18, 2021; Published: January 25, 2021 


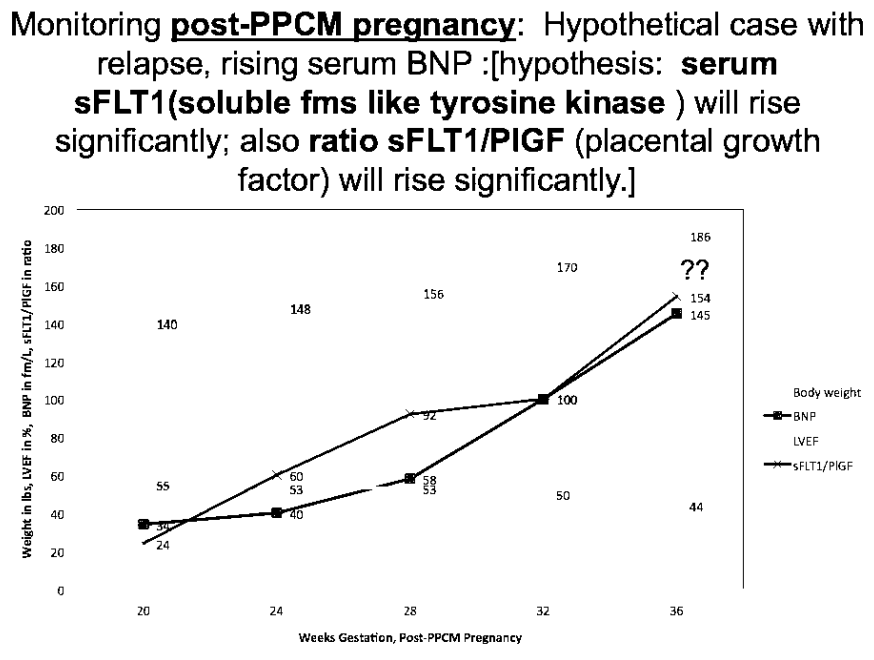

Figure 1. What happens to soluble fms-like tyrosine kinase (sFT1) and placental growth factor (PIGF) in post-PPCM pregnancies?

1. Orthopnea (difficulty breathing when lying flat): (a) None 0 points; (b) Need to elevate head 1 point; (c) Need to elevate 45 degrees or more 2 points.

2. Dyspnea (shortness of breath on exertion): (a) None $\square 0$ points; (b) Climbing 8 or more steps $\square 1$ point; (c) Walking on level 2 points.

3. Unexplained cough: (a) None $\square 0$ points; (b) At night 1 point; (c) Day and night 2 points.

4. Swelling (pitting edema) lower extremities: (a) None $\square 0$ points; (b) Below knee 1

point; (c) Above and below knee 2 points.

5. Excessive weight gain during last month of pregnancy: (a) Under 2 pounds per week $\square$ points; (b) 2 to 4 pounds per week $\square 1$ point; (c) Over 4 pounds per week 2 points.

6. Palpitations (sensation of irregular heartbeats): (a) None 0 points; (b) When lying

down at night $\square 1$ point; (c) Day and night, any position 2 points.

\section{Figure 2. What is your score on this "Self-Test?"}

Self-test for recognition of heart failure during or just after pregnancy*ACTION: 5 or more points $=$ see cardiologist re: plasma BNP and echocardiogram

*Fett JD. Validation of a self-test for early diagnosis of heart failure in peripartum cardiomyopathy. Crit Pathw Cardiol 2011;10 (Mar):44-45.

will gradually decrease as you improve. Final and best indicator is the echocardiographic LVEF. A full echo each time is not necessary, just a "quick-look" for LVEF number will tell what you want to know: namely, a rising LVEF.

\section{How long should my treatment continue?}

It is important to review all factors that relate to the unique situation of any PPCM mother. Non-recovery at one-year post-diagnosis is not the end of the line. Full recovery is still possible. Is the dosage of the medications used adequate and could an increase be tolerated? Is the combination of medications appropriate or does another need to be added (such as the addition of the NI contained in Entresto? Has a cardiac MRI (CMR) been done and does it reveal any late Gadolinium enhancement (LGE), representing irreversible loss of cardiomyocytes? [15,16].

\section{$\mathrm{OK}, \mathrm{I}$ am recovered-What are my risks for relapse?}

Solid recovery and relapse-free course (with or without subsequent pregnancy) are possible [1,2]. Soluble fms-like tyrosine kinase-1 (sFLT1), elaborated by the placenta initially and subsequently by vascular endothelium, is anti-angiogenic, pro-inflammatory and cardiotoxic in the development of PPCM. Placental growth factor (PlGF) is pro-angiogenic, anti-inflammatory and cardio protective. Balance of these angiogenic factors is critical as pregnancy progresses (Figure 1) [16]. There appears to be less risk of developing both preeclampsia, and gestational hypertension if serum sFLT1 $<100 \mathrm{pg} / \mathrm{ml}$ and/or the ratio of serum sFLT-1 to Placental Growth Factor (PIGF) is less than 30 to 40 range at 12 weeks gestation in first or subsequent pregnancy [16]. There is also growing evidence that this observation also applies to PPCM [1]. Above that range makes even closer supervision advisable in order to make an earlier, even prenatal, diagnosis of first time PPCM or relapse in a subsequent pregnancy. The simple, "no-cost" self-assessment test that helps with an earlier diagnosis of heart failure during pregnancy [12] (Figure 2). Scores over 4 indicate need for additional testing.

Serum B-type Natriuretic Peptide (BNP) often rises before any significant fall in LVEF. This provides the potential that a tool that targets sFLT-1 suppression (such as low-dose aspirin from weeks 10 to 32 gestation) can be applied, helping PPCM subjects have better outlook for more rapid and full recovery; if not actual prevention of progression to a diagnosis of PPCM [16-20]. Heart failure medications beta-blockers, ACE-Inhibitors (ACEI) and Angiotensin 2-receptor blockers (ARB) may also have beneficial anti-sFLT1 impact [20-23]. Has FULL recovery occurred? It would be reassuring that has happened if not only return to LVEF of $55 \%$ and no diastolic dysfunction, but also normal left ventricular strain patterns $[24,25]$.

\section{Why did I develop PPCM in the first place?}

This is a work in progress, identifying all the risk factors. We still have much to learn; but here are the ones we know about now:

1. Pregnancy. Incidence of PPCM varies from 1 in 300 pregnancies to 1 in 4000 or more pregnancies [1,2].

2. Gestational hypertension or preeclampsia or eclampsia $[2,16]$.

3. Genetics: Certain genes confer a higher risk for the development of PPCM. In addition, one could have the genetic "Familial Dilated Cardiomyopathy" that only begins to appear under the stress of pregnancy [26].

4. Obesity/Increased Body Mass Index [27].

5. Immune system dysfunction with abnormal immune function cells [28]. There can be a variety of reasons for these, still being identified.

6. Some viral infections occurring just before or during or just after pregnancy. The list is growing; for example, it appears that the pandemic COVID-19 virus is capable of causing a myocarditis or pericarditis with subsequent cardiomyopathy leading to heart failure $[29,30]$.

\section{References}

1. Fett JD (2014) Peripartum cardiomyopathy: A puzzle closer to solution. World $J$ Cardiol 26: 87-99. [Crossref]

2. McNamara DM, Elkayam U, Alharethi R, Damp J, Hsich E, et al. (2015) Clinical outcomes for peripartum cardiomyopathy in North America: results of the IPAC Study (Investigations of Pregnancy-Associated Cardiomyopathy). J Am Coll Cardiol 66: 905914. [Crossref]

3. Fett JD (2020) Editorial: Promoting full recovery and improved relapse-free prognosis in the diagnosis and treatment of peripartum cardiomyopathy. J Am Coll Cardiol 76: 43-45. [Crossref]

4. Fett JD (2020) Editorial: Promoting awareness of peripartum cardiomyopathy (PPCM) Int J Cardiol 305:113-114. [Crossref]

5. Baris L, Cornette J, Johnson MR, Sliwa K, Roos-Hesselink JW (2019) Peripartum Cardiomyopathy: Disease or Syndrome? Heart 105: 357-362.

6. Fett JD (2019) No mother should die of peripartum cardiomyopathy. J Cardiol Diag Res 1:35-37. 
7. Yancy CW, Jessup M, Bozkurt B, Butler J, Casey DE Jr, et al. (2017) ACC/AHA/ HFSA Focused Update of the 2013 ACCF/AHA Guideline for the management of heart failure: A report of the American College of Cardiology/American Heart Association Task Force on Clinical Practice Guidelines and the Heart Failure Society of America. Circulation 136: e137-e161. [Crossref]

8. Hilfiker-Kleiner D, Haghikia A, Berliner D, Vogel-Claussen J, Schwab J, et al. (2017) Bromocriptine for the treatment of peripartum cardiomyopathy: a multicenter randomized study. Eur Heart J 38: 2671-2679. [Crossref]

9. Haghikia A, Podewski E, Libhaber E, Labidi S, Fischer D, et al. (2013) Phenotyping and outcome on contemporary management in a German cohort of patients with peripartum cardiomyopathy. Basic Res Cardiol 108: 366. [Crossref]

10. Fett JD (2018) More study still needed on the use of bromocriptine in the treatment of peripartum cardiomyopathy. Eur Heart J 39: 3904. [Crossref]

11. McNamara DM, Elkayam U, Cooper L, Fett JD, et al. (2016) Reply: Comparison of the American PPCM Registry data with International Registries. J Am Coll Cardiol 16: 734-735. [Crossref]

12. Kurbanov RD, Mirzarakhimova ST, Abdullaev ST, Tsoy IA (2020) The effect of bromocriptine on clinical and laboratory parameters in patients with peripartum cardiomyopathy. Kardiollogiia 60: 984. [Crossref]

13. Fett JD, Murphy JG (2006) Infant survival in Haiti after maternal death from peripartum cardiomyopathy. Int J Gynaecol Obstet 94: 135-136. [Crossref]

14. Fett JD (2011) Validation of a self-test for early diagnosis of heart failure in peripartum cardiomyopathy. Crit Pathw Cardiol 10: 44-45. [Crossref]

15. Schelbert EB, Elkayam U, Cooper LT, Givertz MM, Alexis JD, et al. (2017) Myocardial damage detected by Late Gadolinium Enhancement cardiac magnetic resonance is uncommon in peripartum cardiomyopathy. $J$ Am Heart Assoc 6: e005472. [Crossref]

16. Zhu X, Chen L, Li R (2020) Values of serum sFLt-1, PlGF levels, and sFLt-1/PlGF ratio in diagnosis and prognosis evaluation of preeclamptic patients. Clin Exp Hypertens 42 601-607. [Crossref]

17. Davis MB, Arany Z, McNamara DM, Goland S, Elkayam UJ (2020) Peripartum Cardiomyopathy: JACC State-of-the-Art Review. J Am Coll Cardiol 75: 207-221. [Crossref]

18. Patten IS, Rana S, Shabul S, Rowe GC, Jang C, et al. (2012) Cardiac angiogenic imbalance leads to peripartum cardiomyopathy. Nature 485:333-336. [Crossref]
19. Damp JA, Arany Z, Fett JD, Blauwet L, Elkayam U (2018) Imbalanced angiogenesis in peripartum cardiomyopathy (PPCM). Circ J 82: 2689. [Crossref]

20. Puguero A, Fernandez-Bianco L, Mazarico E, Benitez L, Gonzalez A, et al. (2020) Added prognostic value of longitudinal change of angiogenic factors in early-onset severe preeclamsia: A prospective cohort study. BJOG: 1638. [Crossref]

21. Binder NK, Brownfoot FC, Beard S, Cannon P, Nguyen TV, et al. (2020) Esomeprazole and sulfasalazine in combination additively reduce sFLT-1 secretion and diminish endothelial dysfunction: potential for a combination treatment for preeclampsia. Pregnancy Hypertens 22: 86-92.

22. Carr DB, Tran LT, Brateng DA, Kawamura C, Shofer JB, et al. (2009) Hemodynamically directed atenolol therapy is associated with a blunted rise in maternal sFLT-1 levels during pregnancy. Hypertens Pregnancy 28: 42-55. [Crossref]

23. Fett JD, Fristoe KL, Welsh SN (2010) Risk of heart failure relapse in subsequen pregnancy among peripartum cardiomyopathy mothers. Int J Gynecol Obstet 109: 34 36. [Crossref]

24. Fett JD, Shah T, McNamara DM (2015) Why do some recovered peripartum cardiomyopathy mothers experience heart failure with a subsequent pregnancy? Curr Treat Options in Cardiovasc Med 17: 354 [Crossref]

25. Sugahara M, Kagiyama N, Hasselberg NE, Blauwet LA, Briller, et al. (2019) Global Left Ventriclar Strain at Presentation is Associated with Subsequent Recovery in Patients with Peripartum Cardiomyopathy. J Am Soc Echocardiogr 32:1565-1571. [Crossref]

26. Sheppard R, Hsich E, Damp J, Elkayam U, Kealey A, et al. (2016) GNB3C825T Polymorphism and Myocardial Recovery in Peripartum Cardiomyopathy: Results of the Multicenter Investigations of Pregnancy-Associated Cardiomyopathy Study. Circ Heart Fail 9: e002683. [Crossref]

27. Davis EM, Ewald G. Givert MM, Rajagopaian N, Cooper LT Jr, et al. (2019) Materna Obesity Affects Cardiac Remodeling and Recovery in Women with Peripartum Cardiomyopathy. Am J Perinatol 36: 476-483. [Crossref]

28. McTiernan CF, Morel P, Cooper LT, Raiagopalan N, Thohan V, et al. (2018) Circulating T-Cell Subsets, Monocytes, and Natural Killer Cells in Peripartum Cardiomyopathy: Results from the Multicenter IPAC Study. J Card Fail 24: 33-42. [Crossref]

29. Fett JD (2006) Viral particles in endomyocardial biopsy tissue from peripartum cardiomyopathy patients. Am J Obstet Gynecol 195: 330-331. [Crossref]

30. Fett JD (2007) Viral infection as a possible trigger for the development of peripartum cardiomyopathy. Int J Gynaecol Obstet 97:149-150. [Crossref]

Copyright: (C2021 Fett JD. This is an open-access article distributed under the terms of the Creative Commons Attribution License, which permits unrestricted use, distribution, and reproduction in any medium, provided the original author and source are credited. 